\title{
Opening Lecture
}

\section{The ancestral human diet: what was it and should it be a paradigm for contemporary nutrition?}

\author{
S. Boyd Eaton \\ Departments of Anthropology and Radiology, Emory University, Atlanta, GA 30327, USA
}

\begin{abstract}
Awareness of the ancestral human diet might advance traditional nutrition science. The human genome has hardly changed since the emergence of behaviourally-modern humans in East Africa $100-50 \times 10^{3}$ years ago; genetically, man remains adapted for the foods consumed then. The best available estimates suggest that those ancestors obtained about $35 \%$ of their dietary energy from fats, $35 \%$ from carbohydrates and $30 \%$ from protein. Saturated fats contributed approximately $7.5 \%$ total energy and harmful trans-fatty acids contributed negligible amounts. Polyunsaturated fat intake was high, with $n-6: n-3$ approaching $2: 1$ ( $v .10: 1$ today). Cholesterol consumption was substantial, perhaps $480 \mathrm{mg} / \mathrm{d}$. Carbohydrate came from uncultivated fruits and vegetables, approximately 50\% energy intake as compared with the present level of $16 \%$ energy intake for Americans. High fruit and vegetable intake and minimal grain and dairy consumption made ancestral diets base-yielding, unlike today's acid-producing pattern. Honey comprised 2-3\% energy intake as compared with the $15 \%$ added sugars contribute currently. Fibre consumption was high, perhaps $100 \mathrm{~g} / \mathrm{d}$, but phytate content was minimal. Vitamin, mineral and (probably) phytochemical intake was typically 1.5 to eight times that of today except for that of $\mathrm{Na}$, generally $<1000 \mathrm{mg} / \mathrm{d}$, i.e. much less than that of $\mathrm{K}$. The field of nutrition science suffers from the absence of a unifying hypothesis on which to build a dietary strategy for prevention; there is no Kuhnian paradigm, which some researchers believe to be a prerequisite for progress in any scientific discipline. An understanding of human evolutionary experience and its relevance to contemporary nutritional requirements may address this critical deficiency.
\end{abstract}

Human evolution: Dietary recommendations: Ancestral human diet: Health promotion

Contemporary nutritional advice is based heavily on epidemiological research findings. Grant funding, academic publications, official recommendations, conferences and popular media accounts related to diet commonly reflect an underlying presupposition that the epidemiological method has the greatest scientific validity as well as the most potential for elucidating human nutritional requirements. The present paper suggests there is an alternative or, better, a complementary investigative discipline that should inform the field of nutrition science. The goals would be to better organize and re-interpret previous research findings, to provide direction for future studies and, ultimately, to integrate basic science and public health promotion efforts into a seamless, understandable and logicallyconvincing framework. The underlying principles are straightforward. Humanity's gene pool was selected when man's remote ancestors lived as Stone Age hunter-gatherers (HG). There have been few subsequent genetic changes despite the agricultural and industrial innovations of recent millennia. Hence, optimal human nutrition in the present should reprise the essentials of what it was for the earliest behaviorally-modern ancestors of $50 \times 10^{3}$ years ago (kya).

\section{The ancestral human diet}

\section{Palaeoanthropological background}

The specific evolutionary lineage that has ultimately led to contemporary humans began with a split from the ancestors of today's chimpanzees (Pan troglodytes) and

\footnotetext{
Abbreviations: HG, hunter-gatherer; kya, $\times 10^{3}$ years ago.

Corresponding author: Professor S. Boyd Eaton, fax +1 404352 2529, email sboydeaton@comcast.net
} 
bonobos (Pan paniscus) $\geq 6 \times 10^{6}$ years ago. Thereafter, prehuman antecedents developed upright posture and bipedalism, brain size increased slightly and they learned to use rudimentary stone tools (Klein, 1999) The subsistence activities of these incipient humans at first resembled those of other higher primates, but after about $2.5 \times 10^{6}$ years ago animal meat became an increasingly-important dietary component, via scavenging and/or hunting. Also, previously-little-utilized plant resources, underground storage organs such as roots and tubers, became more accessible (via use of digging sticks) and digestible (as ancestral acquisition of fire allowed development of cooking; Ragir, 2000). Food procurement gradually assumed a gender-specific character with men hunting and/or scavenging and women gathering. Concurrently, height increased until by $1.7 \times 10^{6}$ years ago these ancestors were about as tall as are current humans (Walker \& Leakey, 1993).

These developments took place in northeast Africa, but after about $2 \times 10^{6}$ years ago early humans emigrated to the more clement portions of southern Eurasia. The best accepted current theory is that these migrants contributed little or nothing to the gene pool of today's humans (Klein, 1999) Rather, those ancestors (Homo erectus and Homo ergaster) who continued to live in Africa became ever more modern in their physical and behavioural attributes, attaining essentially complete anatomic equivalence with contemporary humans as early as 200-150 kya (McDougall et al. 2005). Behavioural modernity, the appearance of fullyarticulate speech, intelligence and creativity just like that of man today, is believed to have emerged in Africa between 100 and 50 kya (Klein, 1999) Thereafter, a second wave of true human migrants led to the extinction of their cousins (most famously the Neanderthals) throughout Eurasia (Klein, 1999). During the millennia after this watershed human adaptation to changing bioenvironmental circumstances across their newly-encountered worldwide range was increasingly by cultural innovation rather than genetic modification. Most palaeoanthropologists (Klein, 1999), human geneticists (Neel, 1994) and evolutionary theorists (Gould, 1980) concur that the average individual living now is almost identical, genetically, to his/her ancestors of $50 \mathrm{kya}$.

\section{Temporal and geographical considerations}

After about 50 kya the ambient circumstances of ancestral humans varied with time period and geographical location. This inconstancy has been held by some researchers to invalidate any 'Palaeolithic Prescription'. If there was no one universal lifestyle pattern, how can past experience provide a model for dietary recommendations in the present? There are two logical responses to this objection. The first response is that differences between ancestral environments across time and space were minor in contrast with human experience in the affluent present (Eaton et al. 2002). Whether Stone Age humans lived 45 or $15 \mathrm{kya}$, food was derived form naturallyoccurring vegetation, wild game or aquatic resources. In both the Arctic and the tropics vigorous physical exertion was essential. Reproductive experience varied little amongst preagricultural humans (especially when compared with that of women in contemporary Western nations). Furthermore, for the great majority socio-economic equality was the norm.
Ancestral ways of life during the period from 50 to $10 \mathrm{kya}$ were indeed heterogeneous, but their core essentials were similar and differed strikingly from those of the present. Those central characteristics of life in the past broadly define appropriate goals for health promotion in the present.

Second, the setting for human genetic evolution was African; the genetic makeup of the earliest behaviourallymodern humans was selected for the ways of life of the equatorial African savanna. Although subsequent humans colonized rainforests, the Arctic and arid lands, they accomplished these environmental transitions primarily via cultural innovation. Concomitant genetic adaptation was minimal and largely superficial, as indicated by human intraspecific genetic similarity that is far more uniform than that of gorillas (Gorilla gorilla), chimpanzees and nearly all other mammalian species. Finns and Australian Aborigines are closer, genetically, than are gorillas living $500 \mathrm{~km}$ apart in central Africa (Ruvolo et al. 1994) Any 'Palaeolithic Prescription' should be based on the bioenvironmental conditions that existed in east Africa 50 kya.

\section{Data sources}

Reconstructing the way of life of Stone Age humans is a fascinating, if often frustrating, endeavour. There are several categories of data. Human skeletal remains are amenable to gross anatomical, microscopic, biomechanical and radioisotopic analysis. Archaeological finds, mainly at living sites, include the bones of animals and fish consumed, botanical remains (including electron microscopy of pollen, spores, seeds, husks, etc.), implements and cave or rock wall paintings. HG (or forager) groups studied during the last century were the best, if imperfect, surrogates for Palaeolithic humans. Their subsistence patterns, obligatory physical activity and biomarkers (serum cholesterol levels, blood pressure, glucose responsiveness, BMI, etc.) can be considered representative of those for humans living 50-25 kya. Proximate analyses of the game animals, fish, shellfish and uncultivated plant foods consumed by HG provide further information concerning nutrient intake of those ancestors.

Available evidence is thus indirect. It is not possible to obtain blood samples from, biopsy, visually observe or interrogate the Stone Age humans of 25 kya. Nevertheless, by dint of ongoing multidisciplinary efforts, a defensible and increasingly-detailed picture is emerging. It affords a view of the nutritional pattern for which the human genome was originally intended, as it provides an understanding of the epigenetic milieu within which that diet and human genes interacted.

\section{The specifics of ancestral nutrition}

Method

The following estimates are based on a model that has been gradually refined since its introduction 20 years ago (Eaton \& Konner, 1985) and is best described by Cordain et al. (2000).

\section{Lipids}

Total fat intake. HG, unlike affluent Westerners, consume all edible components of the animals they kill 
(including fat, organs, brain, marrow, etc.), not just that in muscle meat, hence the estimate for total ancestral fat intake is about $35 \%$ total energy intake (Cordain et al. 2000). Fat intake for Palaeolithic $\mathrm{HG}$ varied drastically with latitude (e.g. $>60 \%$ fat in Arctic regions and $<25 \%$ fat in certain tropical locations; Cordain et al. 2000); the $35 \%$ estimate is for Stone Age humans in northeast Africa, the region currently thought most pertinent to the establishment of the contemporary human genome. A total fat intake of $35 \%$ total energy intake is at the upper limit of the acceptable range proposed recently by the Institute of Medicine (2002) of 20-35\% total energy intake and above the upper limit of $30 \%$ total energy intake set by numerous other authoritative organizations (for example, see Food and Nutrition Board, National Research Council, 1989).

Saturated fats. Even though fat provided a substantial proportion of total energy for Stone Age humans, the contribution of saturated fat was lower than that in the average contemporary Western diet; American adults obtain 11-12\% total dietary energy from saturated fat (Institute of Medicine, 2002). Partially-acculturated Greenland Eskimos obtain 8.4\% total dietary energy from saturated fat (Bank \& Dyerberg, 1980) and the estimate for Palaeolithic humans is lower still, perhaps $7.5 \%$ total dietary energy from saturated fat (Eaton et al. 1997; Cordain et al. 2000). While its composition varies seasonally, the fat of wild animals (including that from muscle meat, brain, organs, bone marrow and storage depots) tends to have more MUFA and PUFA and less saturated fatty acid than is found in supermarket meat (Cordain et al. 2002b).

Early recommendations for saturated fat intake (for example, see Food and Nutrition Board, National Research Council, 1989) were $<10 \%$ total energy intake. The Institute of Medicine (2002) now suggests neither a specific RDA nor a tolerable upper intake level for saturated fats, but notes that any incremental increase in saturated fatty acid intake raises CHD risk.

Trans-fatty acids. Ancestral humans did obtain a minimal amount of trans-fatty acids from their mother's milk during infancy and from the flesh of certain herbivores (wild ruminant flesh contains small (3-5\%) amounts of trans-11-vaccenic acid and cis-9, trans-1-conjugated dienes). After absorption these fatty acids are largely converted to cis-9, trans-11conjugated linoleic acid isomers, for which limited evidence indicates anti-carcinogenic and anti-atherogenic activity (Kritchevsky et al. 2000; Institute of Medicine, 2002), but the total percentage from these sources was small in relation to that now consumed by Americans, which largely because of new manufacturing processes such as hydrogenation approaches $2 \%$ total energy intake (Institute of Medicine, 2002).

Polyunsaturated fats. In the USA total PUFA consumption is estimated to average about $15 \mathrm{~g} / \mathrm{d}$, with $n$ - 6 PUFA intake about ten times that of $n-3$ PUFA (Institute of Medicine, 2002). The best available estimate of ancestral human intake suggests that total PUFA intake was nearly twice present levels, almost entirely a result of more $n-3$ PUFA so that $n-6: n-3$ was closer to unity, perhaps $2: 1$ (Eaton et al. 1998; Cordain et al. 2002a). Current US recommendations are quite different, about 8:1 (Institute of Medicine, 2002).

Most contemporary $n-6$ and $n-3$ PUFA intake occurs as $\mathrm{C}_{18} n-6$, linoleic acid $(18: 3 n-6)$, and $\mathrm{C}_{18} n$-3, $\alpha$-linoleic acid $(18: 3 n-3)$. These PUFA can be converted slowly to longer-chain derivatives, arachidonic acid (20:4n-6), EPA $(20: 5 n-3)$ and DHA $(22: 6 n-3)$, which appear to be more important structurally as membranous constituents and biochemically as eicosanoid precursors and biological response modifiers. The fatty acid profile of wild game animals differs greatly from that of grain-fed commercial stock (Cordain et al. 2005), making it likely that ancestral humans had higher total intakes of these longer-chain PUFA, probably ten times as much or more, and that the proportion of $n-3$ forms (EPA and DHA) relative to the chief $n-6$ constituent (arachidonic acid) was substantially greater than at present, an arachidonic acid:EPA + DHA of from 1.5 to $2 \cdot 0$ (Eaton et al. 1998; Cordain et al. 2002a). The Institute of Medicine (2002) recommends that EPA and DHA intake is $\leq 10 \%$ total $n-3$ PUFA intake. This level accords well with retrojected Stone Age experience, but total ancestral EPA + DHA intake would still have been much higher than at present because of higher total $n-3$ PUFA intake.

Dietary cholesterol. Recent HG cholesterol intake was generally greater (approximately $480 \mathrm{mg} / \mathrm{d}$; Eaton \& Konner, 1985; Eaton et al. 1997) than that of Americans today (approximately $260 \mathrm{mg} / \mathrm{d}$; Institute of Medicine, 2002) because of the high consumption of animal flesh; whether from fat or lean animals all cell membranes contain cholesterol. Nevertheless, mean total serum cholesterol levels for five groups of $\mathrm{HG}$ (from three continents) average $3 \cdot 2 \mathrm{mmol} / \mathrm{l}$ (12.3 mg/l; Eaton et al. 1988) v. $5 \cdot 3 \mathrm{mmol} / \mathrm{l}(20 \cdot 0-21 \cdot 0 \mathrm{mg} / \mathrm{l})$ for present-day Americans. LDL and HDL fractionation of HG serum cholesterol has not been recorded (to the author's knowledge) but a total serum value of $3.2 \mathrm{mmol} / \mathrm{l}(12 \cdot 3 \mathrm{mg} / \mathrm{l})$ corresponds approximately to the recently-suggested LDL target of $1.8 \mathrm{mmol} / \mathrm{l}(7 \cdot 0 \mathrm{mg} / \mathrm{l})$ for high-risk coronary disease patients. Furthermore, the HG cholesterol value falls within the range found among free-living non-human primates (Eaton, 1992). That HG cholesterol intake and serum levels seem inversely related to American experience adds to the growing evidence that dietary cholesterol is not a major independent driver of serum cholesterol (Sinclair, 1992; Cordain et al. 2002a).

\section{Protein}

Recently-studied HG protein consumption varies with latitude, but in equatorial savanna populations, those most like the core group of ancestral humans, protein provides about $30 \%$ daily energy intake (Eaton \& Konner, 1985; Eaton et al. 1997; Cordain et al. 2000), which corresponds to an intake of approximately $3 \mathrm{~g} / \mathrm{kg}$ per d for a $70 \mathrm{~kg}$ individual consuming $12500 \mathrm{~kJ}(3000 \mathrm{kcal}) / \mathrm{d}$. This intake greatly exceeds the RDA most recently recommended by the Institute of Medicine (2002) of $0.8 \mathrm{~g} / \mathrm{kg}$ per d, but is well within the range observed for free-living higher primates $(1.6-5.9 \mathrm{~g} / \mathrm{kg}$ per d; Eaton et al. 1997). Despite proposing an RDA, the Institute of Medicine (2002) states that 'for adults, protein intake may range from 10 to 35 percent of energy intake to ensure a nutritionally adequate diet.' (The Institute of Medicine (2002) comprehensive literature survey has failed to establish a definite (or even strongly suggestive) linkage between high protein intake and osteoporosis, nephrolithiasis, renal failure, coronary artery disease, obesity, or cancer.) 


\section{Carbohydrate}

Contemporary Americans obtain about $50 \%$ of their daily energy from carbohydrate, of which about $15 \%$ is contributed by added sugar (sugars added to foods during processing, preparation or consumption). In regions in which behaviourally-modern humans probably originated, ancestral carbohydrate consumption is thought to have made up about 35\% total energy intake (Cordain et al. 2000), of which perhaps $2-3 \%$, on average, came from honey, the closest Palaeolithic parallel for added sugar (Cordain et al. 2005). Cereal grains ( \% total; refined grain 85, whole grain 15) are currently the largest single carbohydrate source, with dairy products another important contributor (Cordain et al. 2005). Man's ancestors had no dairy products after weaning, and rarely used cereal grains, so most of their carbohydrate came from fruits and vegetables, which generally have more desirable glycaemic responses than do cereal grain and dairy products. Fruits and vegetables now provide only $23 \%$ total carbohydrate intake.

The Institute of Medicine (2002) proposes that an acceptable range of carbohydrate intake ( $\%$ total energy intake) is from 45 to 65 (for adults) and that added sugars provide $\leq 25 \%$ total energy. If added sugar was almost wholly eliminated, the resulting carbohydrate contribution to daily energy intake would approximate quantitatively to the Palaeolithic experience. For qualitative equivalence, nearly all carbohydrate would have to be derived from fruits and vegetables rather than dairy or cereal grain products.

\section{Fibre}

Proximate analyses of uncultivated vegetables and fruits consumed by recent HG show that they are substantially more fibrous ( $133 \mathrm{~g}$ dietary fibre $/ \mathrm{kg}$ ) than are those now commercially available $(42 \mathrm{~g} / \mathrm{kg})$, which have been modified by millennia of selective agricultural practice (Eaton, 1990). Hence, the high intake of wild plant foods by ancestral humans necessarily provided a great deal of fibre.

Calculation of ancestral dietary fibre intake, based on a 50:50 animal-vegetable subsistence ratio (as opposed to the 1985 estimate of $35: 65$ ), suggests an average total fibre intake of $>100 \mathrm{~g} / \mathrm{d}$. The Institute of Medicine (2002) now suggests that an adequate intake of total fibre from food ranges from $25 \mathrm{~g} / \mathrm{d}$ for adult women to $38 \mathrm{~g} / \mathrm{d}$ for adult men, values that are approximately twice the current median intake for Americans. The Institute of Medicine (2002) has found insufficient evidence to set a tolerable upper intake level for dietary fibre. A high fibre intake may adversely affect mineral bioavailability, especially when phytate is present. Phytic acid is a prominent constituent of many cereal grains, but is minimally, if at all, present in most uncultivated fruits and vegetables. Consequently, the high fibre content of ancestral diets would probably have had less impact on mineral bioavailability than would a similarly high intake of fibre from contemporary sources (Eaton, 1990; Eaton et al. 1997).

By definition, dietary fibre is not digested by mammalian enzymes and passes relatively intact into the large intestine, where a proportion is fermented by gut microflora. Fruits and vegetables contain fibre that is more completely fermentable than that found in cereals, a distinction that appears to influence the physiological and health effects related to fibre intake. The overall fermentability of ancestral dietary fibre would have much exceeded that typically found in today's fibre-containing foods.

\section{Energy}

Extrapolation from the estimated daily energy intake of foragers studied in the past century suggests that the taller and comparably-active humans of $50 \times 10^{3}$ years ago probably consumed about $11720 \mathrm{~kJ}(2800 \mathrm{kcal}) / \mathrm{d}$ (averaged for men and women; Cordain et al. 1998; Eaton \& Eaton, 2003). Despite the typically higher energy density of contemporary diets (Eaton \& Cordain, 1997), the best available data suggest that the mean energy intake for contemporary Americans is much less, about $8400 \mathrm{~kJ}$ $(2007 \mathrm{kcal}) / \mathrm{d}$ (males $10500 \mathrm{~kJ}$, females $7000 \mathrm{~kJ}$; Institute of Medicine, 2002). Nevertheless, recently-studied HG have BMI averaging $21 \cdot 2 \mathrm{~kg} / \mathrm{m}^{2}$ (Jenike, 2001), well within the accepted normal range $\left(18 \cdot 5-25 \mathrm{~kg} / \mathrm{m}^{2}\right.$; Institute of Medicine, 2002). The present American average BMI is $26.5 \mathrm{~kg} / \mathrm{m}^{2}$. Forager skinfold thicknesses are typically half or less than half those of age-matched contemporary North Americans (Eaton et al. 1988). Further, skeletal remains show that Palaeolithic humans developed muscularity similar to that of today's superior athletes, substantially greater than that of typical males and females (Eaton \& Eaton, 2003). These findings suggest that human ancestors existed within a metabolic environment of high-energy throughput characterized by both greater energy intake and greater energy expenditure than is now the case.

Most contemporary recommendations for energy intake revolve around consumption commensurate with energy expenditure in order to achieve energy balance (assuming pre-existing desirable body weight). That Americans are becoming ever more obese while consuming far less food energy than did ancestral humans is convincing evidence against the efficacy of hypoenergy dieting alone and evidence for increasing physical activity in contemporary lifestyles.

\section{Acid-base considerations}

Ancestral diets were net base yielding because of their vegetable and fruit content; they tended to drive systemic $\mathrm{pH}$ toward alkalinity. Conversely, the cereal grains and dairy foods that make up such a large proportion of contemporary diets are net acid yielding and tend to drive $\mathrm{pH}$ toward acidity (Frassetto et al. 2001; Sebastian et al. 2002). Homeostatic mechanisms ordinarily maintain $\mathrm{pH}$ at about $7 \cdot 4$, but over prolonged periods (decades) the corrective metabolic measures necessary to offset persistent acidyielding diets have deleterious effects, including urinary $\mathrm{Ca}$ loss (to balance $\mathrm{H}^{+}$excretion), accelerated skeletal $\mathrm{Ca}$ depletion, calcific urolithiasis, age-related muscle wasting and progressive renal function deterioration (Frassetto et al. 2001).

\section{Micronutrients}

Ancestral diets generally provided more vitamins and minerals than are obtained by typical Americans, whether in absolute terms or relative to energy intake (Eaton \& Konner, 1985; Eaton et al. 1997). The Palaeolithic 
intake:current intake varies with the specific micronutrient being considered, but typically ranges from 1.5 to eight times more for Stone Age humans (Eaton \& Cordain, 1997; Eaton et al. 1997; Eaton \& Eaton, 2000). The RDA for certain micronutrients has been increased in the past few years; for example, that for vitamin $C$ has been raised from $60 \mathrm{mg} / \mathrm{d}$ to $75-90 \mathrm{mg} / \mathrm{d}$ (for women and men respectively). Acceptable upper limits for micronutrients have been proposed by the Institute of Medicine (2000). Except for $\mathrm{Fe}$, all retrojected ancestral intakes fall within these limits. For example, the newly-established acceptable upper limit for vitamin C intake is $2000 \mathrm{mg}$, well above the estimated Palaeolithic average of $513 \mathrm{mg} / \mathrm{d}$.

$\mathrm{Na}$ is a glaring exception to the general rule that Palaeolithic vitamin and mineral intakes exceeded the present intakes. Extrinsic $\mathrm{Na}$ is added to that occurring naturally in foods during processing, preparation and at the table; only $10 \%$ of the $\mathrm{Na}$ intake is intrinsic to the foods that are eaten (Food and Nutrition Board, National Research Council, 1989; Eaton \& Cordain, 1997). For ancestral humans K intake substantially exceeded that of $\mathrm{Na}$; the $\mathrm{K}: \mathrm{Na}$ was probably about 5:1 in northeast Africa. Now, however, $\mathrm{Na}$ intake exceeds that of $\mathrm{K}$. The availability of cheap commercial $\mathrm{Na}$ explains much of this radical electrolytic inversion, but replacement of K-rich fruits and vegetables by K-poor vegetable oils, refined sugars, dairy products and cereals is an additional important factor.

\section{A paradigm for contemporary nutrition}

\section{Nutritional accomplishments}

The food industry, of which nutrition science is an essential element, has achieved extraordinary success. In terms of the time and/or effort required for its acquisition, food energy is more available now than ever before. Evolution is driven by net reproductive success (or, technically, 'inclusive fitness'). The selfish genome succeeds if it passes more copies of itself into subsequent generations than do its competitors. However, reproductive efficiency itself is, in large measure, dependent on an organism's subsistence efficiency; in this sense eating outweighs mating. As a result of unprecedented subsistence efficiency, the human population has grown to number far more individuals than has any other current or previous species of large mammals. That undernutrition and starvation persist reflects political factors and faulty food distribution, not inadequate food production.

In addition, nutrition science should be proud of its role in increasing food safety. Not only is food more affordable, it is also less likely to be tainted by infectious agents than at any time since the advent of agriculture (hormones, heavy metals, pesticides etc. are another issue). These accomplishments in the areas of accessibility and safety are much more important contributors to the present increasing life expectancy than nutritional advances relative to chronic disease prevention could ever be (Eaton et al. 2002).

\section{Failures of nutrition science}

The signal achievements of nutrition science seem to be taken almost for granted, but its shortcomings are a favoured topic in both academic publications and the popular press. Such criticisms are perhaps unfair; however, one legitimate and fundamental weakness should cause deep concern within the nutrition science community. The field has, appropriately, addressed the challenge of health promotion and disease prevention as it pertains to the degenerative illnesses of adulthood. Thus, the bottom line criterion of success or failure is not mortality, but rather disease incidence and prevalence. Furthermore, for most major chronic illnesses, from CHD (Willett, 2002) to hypertension (Hajjar \& Kotchen, 2003) and from obesity to diabetes (Mokdad, 2001), incidence or prevalence now exceeds, or at least is unchanged from, what it was 20 years ago.

An additional negative, which probably contributes to the lack of favourable impact on chronic disease incidence or prevalence, is the inconsistent (and often contradictory) nature of epidemiological findings pertinent to nutrition and health promotion. From the august pages of leading scientific publications (Ioannidis, 2005) to the comic strips of daily newspapers such seemingly erratic results are lamented and ridiculed.

Nutrition's presumably related problems of inconsistency and ineffectiveness suggest that the field might benefit from objective introspection. Is there a basic deficiency that bedevils research efforts and inhibits substantial progress? Thomas Kuhn's (1996) classic treatise, The Structure of Scientific Revolutions, argues that in order to be effective mature sciences must operate under the aegis of a governing paradigm, a gestalt or world view that serves to integrate and coordinate an investigative discipline's endeavours. Kuhn's (1996) ideas have been highly praised and, of course, derided, but they do raise the possibility of a critical defect that weakens and undermines the entire field of nutrition science; there is no basic unifying paradigm. (Kuhn's treatise was initially written in 1962, but Ian Johnson's (2005) Science editorial makes the same point.) Firm belief in the epidemiological method is common among scientists and physicians interested in health promotion, but methodological uniformity differs from and, in Kuhn's (1996) view, cannot substitute for an actual paradigm.

Joel Mokyr (2002), former president of the Economic History Association, claims that a basic paradigm has special importance for health promotion; an understandable, persuasive and logical frame of reference is essential for public acceptance of, and action in line with, authoritative recommendations, no matter how sound the basic research on which they are based.

The lifestyle of ancestral humans, that for which the contemporary genome was originally selected, could be considered a candidate paradigm. Deviation from the essentials of that experience appears to underlie the pathophysiology of chronic disease propagation and, conversely, behaviour that tends to match the Stone Age lifestyle model seems to forestall development of chronic illness while positively enhancing health. As it has usually been presented, the idea of a 'natural' diet has been rightly ridiculed as naïve and simplistic. However, the convergence of increasingly detailed palaeoanthropological understanding together with investigative insights 
arising from a nutrition science informed by evolutionary awareness holds out the promise that this innately appealing concept may at some point make a vital contribution to the prevention of chronic degenerative diseases.

\section{References}

Bang HO \& Dyerberg J (1980) Lipid metabolism and ischemic heart disease in Greenland Eskimos. Advances in Nutrition Research 3, 1-22.

Cordain L, Brand-Miller J, Eaton SB, Mann N, Holt SHA \& Speth JD (2000) Plant-animal subsistence ratios and macronutrient energy estimations in worldwide hunter-gatherer diets. American Journal of Clinical Nutrition 71, 682-692.

Cordain L, Eaton SB, Brand-Miller J, Mann N \& Hill K (2002a) The paradoxical nature of hunter-gatherer diets: meat-based, yet non-atherogenic. European Journal of Clinical Nutrition 56, Suppl. 1, 542-552.

Cordain L, Eaton SB, Sebastian A, Mann N, Lindeberg S, Watkins BA, O'Keefe JH \& Brand-Miller J (2005) Origins and evolution of the Western diet: health implications for the 21st century. American Journal of Clinical Nutrition 81, 341-354.

Cordain L, Gotshall RW \& Eaton SB (1998) Physical activity, energy expenditures and fitness: an evolutionary perspective. International Journal of Sports Medicine 19, 328-335.

Cordain L, Watkins BA, Florant GL, Kehler M, Rogers L \& Li Y (2002b) Fatty acid analysis of wild ruminant tissues: evolutionary implications for reducing diet-related chronic disease. European Journal of Clinical Nutrition 56, 181-191.

Eaton SB (1990) Fibre intake in prehistoric times. In Dietary Fibre Perspectives. vol. 2, Reviews and Bibliography, 2nd ed., pp. 27-40 [AR Leeds, editor]. London: John Libby.

Eaton SB (1992) Humans, lipids and evolution. Lipids 27, 814-820.

Eaton SB \& Cordain L (1997) Evolutionary aspects of diet: old genes, new fuels. World Review of Nutrition and Dietetics 81, 26-37.

Eaton SB, Cordain L \& Lindeberg S (2002) Evolutionary health promotion: a consideration of common counterarguments. Preventive Medicine 34, 119-123.

Eaton SB \& Eaton SB III (2003) An evolutionary perspective on human physical activity: implications for health. Comparative Biochemistry and Physiology 136A, 157-159.

Eaton SB, Eaton SB III \& Konner MJ (1997) Paleolithic nutrition revisited: a twelve year retrospective. European Journal of Clinical Nutrition 51, 207-216.

Eaton SB, Eaton SB III, Sinclair AJ, Cordain L \& Mann NJ (1998) Dietary intake of long-chain polyunsaturated fatty acids during the Paleolithic. World Review of Nutrition and Dietetics 83, 12-23.

Eaton SB \& Konner M (1985) Paleolithic nutrition. A consideration of its nature and current implications. New England Journal of Medicine 312, 283-289.

Eaton SB, Konner M \& Shostak M (1988) Stone Agers in the fast lane: chronic degenerative diseases in evolutionary perspective. American Journal of Medicine 84, 739-749.

Eaton SB III \& Eaton SB (2000) Consumption of trace elements and minerals by preagricultural humans. In Clinical Nutrition of the Essential Trace Elements and Minerals, pp. 37-47 [JD Bogden and LM Klevay, editors]. Totowa, NJ: Humana Press.

Food and Nutrition Board, National Research Council (1989) Recommended Dietary Allowances, 10th ed. Washington, DC: National Academy Press.
Frassetto LA, Morris RC Jr, Sellmeyer DE, Todd K \& Sebastian A (2001) Diet, evolution and aging. The pathophysiological effects of the post-agricultural inversion of the potassiumto-sodium and base-to-chloride ratios in the human diet. European Journal of Nutrition 40, 200-213.

Gould SJ (1980) The Panda's Thumb, p. 83. Toronto, Ont: George J. McLeod.

Hajjar I \& Kotchen TA (2003) Trends in prevalence, awareness, treatment, and control of hypertension in the United States, 1988-2000. Journal of the American Medical Association 290, 199-206.

Institute of Medicine (2000) Dietary Reference Intakes for Vitamin C, Vitamin E, Selenium, and Carotenoids, p. 95. Washington, DC: National Academies Press.

Institute of Medicine (2002) Dietary Reference Intakes. Energy, Carbohydrate, Fiber, Fat, Fatty Acids, Cholesterol, Protein, and Amino Acids. Washington, DC: National Academies Press.

Ioannidis JPA (2005) Contradicted and initially stronger effects in highly cited clinical research. Journal of the American Medical Association 294, 219-228.

Jenike MR (2001) Nutritional ecology: diet, physical activity and body size. In Hunter-Gatherers. An Interdisciplinary Perspective, pp. 205-238 [C Panter-Brick, RH Layton and P RowleyConwy, editors]. Cambridge: Cambridge University Press.

Johnson IT (2005) Cancers of the gut and Western ills. Science 307, 1839.

Kritchevsky D, Tepper SA, Wright S, Tso P \& Czarnecki SK (2000) Influence of conjugated linoleic acid (CLA) on establishment and progression of atherosclerosis in rabbits. Journal of the American College of Nutrition 19, 472S-477S.

Klein RG (1999) The Human Career: Human Biological and Cultural Origins. Chicago, IL: University of Chicago.

Kuhn, TS (1996). The Structure of Scientific Revolutions, 3rd ed., pp. 10-15. Chicago, IL: University of Chicago Press.

McDougall I, Brown FH \& Fleagle JG (2005) Stratigraphic placement and age of modern humans from Kibish, Ethiopia. Nature 433, 733-736.

Mokdad AH, Bowman BA, Ford ES, Vinicor F, Marks JS \& Koplan JP (2001) The continuing epidemics of obesity and diabetes in the United States. Journal of the American Medical Association 286, 1195-1200.

Mokyr J (2002) The Gifts of Athena, pp. 193-195. Princeton, NJ: Princeton University Press.

Neel JV (1994) Physician to the Gene Pool. New York: John Wiley.

Ragir S (2000) Diet and food preparation: rethinking early hominid behavior. Evolutionary Anthropology 9 , 153-155.

Ruvolo M, Pan D, Zehr S, Goldberg T, Driscoll TR \& von Dornum M (1994) Gene trees and hominid phylogeny. Proceedings of the National Academy of Sciences USA 91, 8900-8904.

Sebastian A, Frassetto LA, Sellmeyer DE, Merriam RL \& Morris RC (2002) Estimation of the net acid load of the diet of ancestral preagricultural Homo sapiens and their hominid ancestors. American Journal of Clinical Nutrition 76, $1308-1316$.

Sinclair A (1992) Was the hunter-gatherer diet prothrombotic? In Essential Fatty Acids and Eicosanoids, pp. 318-324 [A Sinclair and R Gibson, editors]. Champaign, IL: American Oil Chemists Society.

Walker A \& Leakey R (editors) (1993) Perspectives on the Nariokotome Homo erectus skeleton. In The Nariokotome Homo Erectus Skeleton, pp. 311-330. Cambridge, MA: Harvard University Press.

Willett W (2002) Nutrition: The food pushers. Science 297, 198-199. 